\title{
CONDIÇÕES E TIPOS DE CÉU PARA SIMULAÇÕES DE ILUMINAÇÃO NATURAL COM CÉU ESTÁTICO
}

\author{
CONDITIONS AND TYPES OF SKY FOR SIMULATIONS OF \\ DAYLIGHTING WITH STATIC SKY
}

\author{
Mariana Vallory Michel ${ }^{1}$ \\ Universidade Federal do Espírito Santo, Vitória, ES, Brasil, marianavallory@yahoo.com.br \\ Andréa Coelho Laranja 2 \\ Universidade Federal do Espírito Santo, Vitória, ES, Brasil, andreacoelholaranja@gmail.com
}

\begin{abstract}
Resumo
As normas brasileiras recomendam que o céu em simulações de iluminação natural seja o mais representativo do local nos solstícios de verão e inverno, mas não fornecem informações suficientes para defini-lo. Entretanto, os dados mais importantes para a definição do céu são os obtidos por equipamentos que medem radiação solar global e difusa - existente em poucas cidades no Brasil. Assim, este artigo tem como objetivo definir as condições de céu e os céus CIE característicos de capitais brasileiras por meio de um método aplicável à realidade do país. Inicialmente, foram selecionadas as capitais do Centro-Sul com disponibilidade de dados diários e mensais de horas de sol do Instituto Nacional de Meteorologia no intervalo de vinte anos (1997-2016). O método escolhido para encontrar as condições de céu foi o simplificado de Duffie e Beckman (2013) com adaptações de Ferreira e Souza (2006). Para os tipos de céu, utilizou-se etapa complementar autoral, que dividiu o percentual de cada condição de céu obtido na etapa anterior pela quantidade de céus CIE na respectiva condição de céu. Os resultados foram ratificados pela comparação com dados de nebulosidade do mesmo ínterim. Assim, a pesquisa estabeleceu uma classificação simplificada de condições e tipos de céu CIE para simulações com céu estático em programas de iluminação natural para Cuiabá, Brasília, Belo Horizonte, Vitória, São Paulo, Curitiba, Florianópolis e Porto Alegre. Ademais, apresenta-se uma metodologia para seleção dos céus característicos, passível de ser replicada para outras cidades brasileiras.
\end{abstract}

Palavras-chave: Céu CIE. Condição de céu. Simulação de iluminação natural.

\begin{abstract}
Brazilian standards recommend that the sky in daylighting simulations be the most representative of the location for summer and winter solstices, but the standards do not provide enough information to define them. However, the essential data for the definition of the sky are those obtained by equipment that measures global and diffuse solar radiation - existing in a few cities in Brazil. Thus, this article aims to define the sky conditions and the characteristic CIE skies of Brazilian capitals through a method applicable to the reality of the country. Initially, the capitals of the Center-South with data availability of daily and monthly sunshine hours from the Instituto Nacional de Meteorologia were selected, considering twenty years (1997-2016). The method, chosen to find the sky conditions, was the simplified one of Duffie and Beckman (2013) with adaptations from Ferreira and Souza (2006). For sky types, an additional step proposed by the authors was used, which divided the percentage of each sky condition obtained in the previous step by the amount of CIE skies with respective sky conditions. The results were ratified by comparison with cloudiness data from the same period. Thus, the research established a simplified classification of conditions and types of CIE sky for simulations with the static sky in daylighting programs for Cuiabá, Brasília, Belo Horizonte, Vitória, São Paulo, Curitiba, Florianópolis and Porto Alegre. Also, a methodology is presented for the selection of typical skies that could be replicated to other Brazilian cities.
\end{abstract}

Keywords: CIE sky. Sky condition. Daylighting simulation.

How to cite this article:

MICHEL, M. V.; LARANJA, A. C. Condições e tipos de céu para simulações de iluminação natural com céu estático. PARC Pesquisa em Arquitetura e Construção, v. 11, p. e020001, 13 mar. 2020. DOI: https://doi.org/10.20396/parc.v11i0.8652766 


\section{Introdução}

Dados locais de radiação solar são importantes para muitas áreas do conhecimento e para diferentes tipos de aplicação. Entre estes, destaca-se neste estudo a aplicação dos dados de radiação solar em termos de luz visível como pré-requisito para obtenção da caracterização do céu de um determinado local como dado de entrada para simulações de iluminação natural.

Segundo Besharat, Dehghan e Faghih (2013), a melhor forma de determinar as radiações solares global e difusa de qualquer lugar é com equipamentos de medição destas variáveis. Entretanto, como esses pesquisadores e Bakirci (2009) apontam, é recorrente a ausência de tais instrumentos em países em desenvolvimento por falta de capacidade técnica e orçamentária em fornecê-los e mantê-los. No Brasil, há apenas dois equipamentos de medição de radiação solar normatizados pelo Guide to Recommended Practice of Daylight Measurement (CIE, 1994): as Estações de Medição de lluminação Natural (EMIN) de Florianópolis e Belo Horizonte (FERREIRA; SOUZA, 2013; SOUZA; PEREIRA, 2004).

Para solucionar a indisponibilidade de dados de radiação solar da maioria das cidades de países como o Brasil, são utilizados métodos baseados em dados meteorológicos disponíveis para caracterização do céu de forma indireta (BAKIRCl, 2009), uma vez que isso normalmente não é possível por meio de dados de estações meteorológicas convencionais (LOU; LI; LAM, 2017). O grande desafio neste caso é selecionar o tipo de dado e o método mais apropriados.

Em relação ao tipo de dados, Besharat, Dehghan e Faghih (2013) defendem que o método tenha como fonte os dados de nebulosidade, embasados na argumentação de que a nebulosidade representa o fenômeno atmosférico mais importante na verificação de disponibilidade de radiação solar na superfície terrestre. Em contrapartida, classificam as horas de insolação como o parâmetro meteorológico mais recomendado, além de o reconhecerem como o mais utilizado devido à facilidade de disponibilidade $e$ medição dos dados. Ademais, ponderam que os dados de temperatura também estão entre os mais usados, mas sua utilização só deve ocorrer em situações de indisponibilidade de dados de nebulosidade e horas de insolação.

Por outro lado, Rangarajan, Swaminathan e Mani (1984) defendem que o número de horas do sol tem fornecido os melhores resultados entre os métodos de computação da radiação solar global e difusa. Além disso, Duffie e Beckman (2013) preterem estimativas visuais - utilizadas na maioria das vezes por indisponibilidade de satélites meteorológicos, detectores dos dados de nebulosidade (SUPIT; VAN KAPPEL, 1998).

Goulart (1993, p. 20), por sua vez, relaciona horas de sol e nebulosidade, constando em seu estudo uma relação inversamente proporcional entre estes dados: "as interrupções nos registros de luz do sol são normalmente causadas pelo sol sendo obstruído por nuvens de certa opacidade". Assim, a autora defende o emprego de qualquer um dos dois tipos de dados, nebulosidade e horas de insolação, para encontrar a característica do céu de acordo com os períodos analisados.

Quanto ao método mais apropriado para definir as radiações solares, Besharat, Dehghan e Faghih (2013) recomendam que seja selecionado um que utilize apenas variáveis meteorológicas diárias, disponibilizadas pela maioria das estações. Os autores apresentam variados modelos para estimar as radiações solares por meio dos dados de horas de insolação e de nebulosidade. As fórmulas correspondentes precisam de dados de entrada de radiação solar, que não são facilmente encontrados para as cidades brasileiras. Em contrapartida, Duffie e Beckman (2013) utilizam apenas a razão do sol - 
obtida por meio da divisão da média mensal de horas de insolação diária pela média mensal da máxima de possibilidades de horas de insolação diária do período escolhido. Este modelo representa o método simplificado dos autores, apresentado inicialmente em 1974 e ratificado mais recentemente em 2013, quando foi validado pelos próprios autores frente a um método matemático mais complexo utilizando as radiações global e difusa.

Nesse cenário, salienta-se que Ferreira e Souza (2006) aplicaram o modelo de razão do sol de Duffie e Beckman (2013) para a realidade brasileira. As autoras também optaram pelo método simplificado em detrimento de um método matemático mais complexo, após comparação dos resultados destes com dados medidos de equipamento de medição de radiação solar - os quais são os mais recomendados, porém indisponíveis para a maioria das cidades do país.

Simulações de lluminação Natural

A verificação da iluminância em um projeto é essencial para melhorar a qualidade lumínica no ambiente interno, trazendo mais conforto visual aos usuários de uma edificação e possibilitando menores gastos com energia. Nesse cenário, os programas de simulação de iluminação natural são fundamentais para profissionais e acadêmicos da área, principalmente em projetos experimentais ou ainda não executados, nos quais a medição in loco não é possível. Essas simulações são definidas em função das condicionantes climáticas de iluminação natural do local. Para isso, é preciso especificar o céu, como supracitado.

A NBR 15.215-4 (ABNT, 2005b) qualifica os métodos de medição do céu em real ou artificial (simulado). Medições com o céu real não são objeto de estudo, pois, "caracterizam-se pela dificuldade de reprodução das condições experimentais" (ABNT, 2005b, p. 14). Isso ocorre porque os momentos de coleta são muito suscetíveis a não representarem uma amostra verídica do período trabalhado frente: às instabilidades do tempo e do clima; à quantidade de dados coletados; e às variações de luminosidade durante um mesmo dia, mês e ano. Já o céu artificial consegue ser adaptado a uma base maior de dados meteorológicos, sendo automaticamente mais representativo do clima local, amenizando assim as incertezas do tempo (JULIAN, 1998).

O céu simulado, utilizado nas simulações computacionais, pode ser classificado em estático ou dinâmico. No Brasil, os programas de iluminação natural que utilizam o céu dinâmico têm como dado de entrada os arquivos climáticos disponibilizados pelo Laboratório de Eficiência Energética em Edificações (2017), assim como pelo site Climate.OneBuilding (2018). Em contrapartida, os softwares que utilizam os céus estáticos ficam muitas vezes à mercê do estabelecimento de um critério para seleção do céu.

A NBR 15.215-4 (ABNT, 2005b) recomenda que o céu deva ser o mais representativo do local nos dias dos solstícios de verão e inverno. Na sua segunda parte (ABNT, 2005a), a norma especifica, de uma forma pouco precisa, como encontrar a condição de céu recomendada. Indica-se a utilização do método da "NOAA (EUA)" que observa a cobertura das nuvens por intermédio de percentuais numa escala de 0 a 100\% (céu claro: 0-35\%; parcial: 35-75\%; e encoberto: 75-100\%).

Dessa forma, a NBR 15.215-4 (ABNT, 2005b) expõe os parâmetros de classificação do céu, mas não aborda como descobrir os percentuais de nebulosidade para cada localidade, além de não especificar qual publicação da NOAA está referenciando. Assim sendo, a norma brasileira, que não identifica sequer o nome da instituição referencial 
por completo, deixa em aberto o método de como definir o céu desejado - dificultando, pois, o atendimento ao seu método recomendado.

Outra ponderação importante sobre os programas de simulação de iluminação natural de céu estático é que, de modo geral, estes softwares requerem como dado de entrada apenas a condição de céu, definida pela NBR 15.215-2 (ABNT, 2005a) como: claro, parcial (ou parcialmente encoberto) e encoberto. Porém, a título de exemplo, o TropLux, programa brasileiro da área recomendado pelo Manual para aplicação do Regulamento Técnico da Qualidade para o Nível de Eficiência Energética de Edificações Residenciais (RTQ-R) (BRASIL, 2012), requer como dado de entrada o tipo de céu da Commission Internationale de l'Eclairage (CIE, 2004) (CABÚS, 2005; CABÚS; VÍTOR, 2015). Os céus CIE (2004) são classificados em quinze tipos, sendo 1 o mais encoberto e 15 o mais claro ( 1 a 5 encoberto; 6 a 10 parcialmente encoberto e 11 a 15 claro). Sua classificação depende de dados de luminância do céu, indisponível em muitos países (ALSHAIBANI, 2017), como é o caso do Brasil, pela escassez de estações específicas para essa finalidade, como levantado na problemática deste artigo.

Como exposto na Tabela 1, existem variações em termos de gradação e indicatriz na distribuição de luminância entre os céus CIE. Porém, as variações são basicamente agrupadas de forma proporcional: quanto maior o céu CIE, maior sua classificação nos grupos de gradação e indicatriz - com exceção dos destacados em vermelho na tabela.

\begin{tabular}{|c|c|c|c|}
\hline Tipo & $\begin{array}{l}\text { Grupo de } \\
\text { gradação }\end{array}$ & $\begin{array}{l}\text { Grupo de } \\
\text { indicatriz * }\end{array}$ & Descrição da distribuição de luminância \\
\hline 1 & I & 1 & $\begin{array}{l}\text { Padrão Céu Nublado CIE, graduação de luminância íngreme em } \\
\text { direção ao zênite, uniformidade azimutal }\end{array}$ \\
\hline 2 & 1 & 2 & $\begin{array}{l}\begin{array}{l}\text { Nublado, com gradação de luminosidade acentuada e leve brilho em } \\
\text { direção ao sol }\end{array} \\
\end{array}$ \\
\hline 3 & II & (1) & Nublado, moderadamente graduado com uniformidade azimutal \\
\hline 4 & II & 2 & Nublado, moderadamente graduado e leve brilho em direção ao sol \\
\hline 5 & III & (1) & Céu de luminância uniforme \\
\hline 6 & III & 2 & $\begin{array}{l}\text { Céu parcialmente nublado, sem gradação em direção ao zênite, } \\
\text { ligeiro clarão em direção ao sol }\end{array}$ \\
\hline 7 & III & 3 & $\begin{array}{l}\text { Céu parcialmente nublado, sem gradação em direção ao zênite, } \\
\text { região circunsolar mais brilhante }\end{array}$ \\
\hline 8 & III & 4 & $\begin{array}{l}\text { Céu parcialmente nublado, sem gradação em direção ao zênite, } \\
\text { corona solar distinta }\end{array}$ \\
\hline 9 & IV & (2) & Parcialmente nublado, com o sol escurecido \\
\hline 10 & IV & 3 & Parcialmente nublado, com uma região circunsolar mais brilhante \\
\hline 11 & IV & 4 & Céu branco-azul com corona solar distinta \\
\hline 12 & $\mathrm{~V}$ & 4 & Padrão Céu Claro CIE, turbidez de baixa luminosidade \\
\hline 13 & $\mathrm{~V}$ & 5 & Padrão Céu Claro CIE, atmosfera poluída \\
\hline 14 & $\mathrm{VI}$ & 5 & Céu turvo sem nuvens com corona solar ampla \\
\hline 15 & $\mathrm{VI}$ & 6 & Céu turvo branco-azul com corona solar ampla \\
\hline
\end{tabular}

Nota:* Refere-se à variação dos índices de refração lumínica nas diferentes direções. Fonte: Adaptado de CIE (2004, tradução nossa, grifo do autor).

Perante esse cenário nacional de limitações de fontes de dados meteorológicos apropriados para caracterização de céu e a exigência (bem como indisponibilidade) de dados de entrada de céu específicos de cada cidade nos programas de simulação de iluminação natural, este artigo objetiva definir de forma simplificada as condições de céu e os céus CIE característicos e aplicáveis à realidade das cidades brasileiras que sirvam como dado de entrada em programas de simulação de iluminação natural de céu estático. 


\section{Método}

Esta pesquisa tem seu campo de abrangência delimitado às capitais brasileiras do Centro-Sul do país que possuem os dados históricos de horas de insolação e nebulosidade disponíveis no Instituto Nacional de Meteorologia (INMET) a partir do Banco de Dados Meteorológicos para Ensino e Pesquisa ${ }^{(1)}$. A seleção do recorte se baseia no fato de o Centro-Sul abrigar a maioria dos estados com as maiores populações (IBGE, 2010). Restringiu-se o estudo às capitais por serem cidades de referência para as unidades federativa. O período considerado para a simulação foi de 20 anos (janeiro de 1997 a dezembro de 2016), conforme orientação de Korachagaon e Bapat (2011). O método selecionado foi o simplificado de Duffie e Beckman (2013) com adaptações de Ferreira e Souza (2006) e autorais, considerando a finalidade dos dados a serem obtidos e a disponibilidade de dados das cidades brasileiras selecionadas.

O método foi escolhido pela simplificação no seu processo para obtenção dos ceús característicos das cidades desejadas e por ser aplicável a qualquer cidade brasileira. Isso porque o método se baseia em horas de insolação - que podem ser obtidas tanto em cidades que possuem estações meteorológicas como nas que não possuem, visto que as horas de insolação são facilmente medidas (BAKIRCI, 2009). Além disso, este método simplificado foi selecionado e aplicado para a realidade brasileira enquanto modelo de estimativa de radiação solar para caracterização de céu frente a modelos mais complexos, cujos dados de entrada são mais precisos (FERREIRA; SOUZA, 2006).

É válido pontuar que o método de obtenção da característica do céu da NBR 15.215-2 (ABNT, 2005a) foi preterido por insuficiência de dados na norma sobre o mesmo; pela vulnerabilidade de um método baseado em estimativa visual; e pela necessidade de dados de radiação como dado de entrada nas fórmulas envolvendo dados de nebulosidade, indisponíveis para a maioria das cidades brasileiras (BESHARAT; DEHGHAN; FAGHIH, 2013; DUFFIE; BECKMAN, 2013).

\section{Sequência metodológica}

Este artigo divide-se em duas etapas metodológicas: 1) determinação da condição do céu; e 2) determinação e ratificação do tipo de céu CIE do local. A primeira etapa se baseia no método simplificado de Duffie e Beckman (2013), utilizando a razão do sol do modelo com parâmetros de classificação da condição do céu de Ferreira e Souza (2006) - que aplicaram o método referencial no contexto brasileiro. A segunda é uma complementação da primeira com adaptações autorais para se encontrar os tipos de céus CIE das mesmas localidades. Salienta-se que esta etapa autoral se baseia em uma simplificação na escala dos céus $\mathrm{CIE}$, ao considerar que quanto maior o número do céu $\mathrm{CIE}$, maior sua luminância, ignorando as situações minoritárias de não proporcionalidade. Tal consideração tem em vista o intuito do artigo de possibilitar um meio de obtenção desses céus como dados de entrada para simulações de iluminação natural com céu estático (como as feitas no programa TropLux) para simulações que não exijam um alto grau de precisão em cidades que não disponham desse tipo de dado. Observa-se que, devido à proposta de simplificação, esta etapa conta com um procedimento de confirmação dos resultados obtidos.

Na primeira etapa, o método simplificado estabelece a condição de céu por meio da razão do sol. Em seguida, com a razão resultante do período escolhido, as condições de céu mensais do local podem ser classificadas segundo parâmetro de Ferreira e Souza (2006). Destaca-se que todos os dados trabalhados são oriundos de coletas feitas diariamente pelo INMET ${ }^{(1)}$, tendo a base de dados diários, como recomenda Besharat, Dehghan e Faghih (2013). Já na segunda etapa, os céus CIE são obtidos dividindo a 
porcentagem total de cada condição de céu pela quantidade de céus CIE daquela condição de céu. Com essas novas porcentagens, possibilitou-se a classificação dos tipos de céu CIE por mês em cada cidade - sendo que esses resultados foram ratificados graficamente como inversamente proporcionais aos dados de nebulosidade disponíveis pelo INMET (1997-2016b), como defendido por Goulart (1993).

Apresentam-se os oito procedimentos metodológicos da pesquisa, sendo os cinco primeiros pertencentes à primeira etapa (determinação da condição de céu) e os três últimos procedimentos pertencentes à segunda etapa metodológica (determinação do tipo de céu):

- $1^{\circ}$ : obtenção dos dados de horas de insolação mensais e diários das capitais;

- $2^{\circ}$ : levantamento geral e seleção das estações do recorte trabalhado;

- $3^{\circ}:$ manipulação dos dados mensais;

- $4^{\circ}$ : manipulação dos dados diários;

- $5^{\circ}$ : definição das condições de céu das capitais - manipulação dos dados dos procedimentos 3 e 4 ;

- $6^{\circ}$ : definição do parâmetro de classificação dos céus CIE;

- $7^{\circ}$ : definição dos céus CIE das capitais - manipulação dos dados do $5^{\circ}$ procedimento;

- $8^{\circ}$ : ratificação dos resultados do $7^{\circ}$ procedimento.

No primeiro procedimento, foram extraídos os dados diários e mensais de cada capital para o intervalo de 01/01/1997 a 31/12/2016 do site do INMET (1997-2016a). Os dados, fornecidos em extensão ".txt", foram transformados em arquivo Excel, sendo gerados dois documentos para cada cidade: um com os dados mensais e outro com os diários.

Com o levantamento desses dados, pôde-se elaborar no segundo procedimento, uma tabela com dados gerais das estações do recorte geográfico trabalhado, identificando: código, capital, unidade federativa, latitude, longitude, altitude, início de operação da estação e o período disponível dos dados. Nessa compilação de dados, foram detectadas: quais capitais não possuíam estação meteorológica; quais estações não possuíam dados de horas de insolação diária e mensal no período abordado; e quais possuíam dados insuficientes para o período - tendo como critério para esse parâmetro um mínimo de cinco anos (WU et al., 2013). As capitais sem estação ou com dados insuficientes foram excluídas e as estações que seriam trabalhadas em seguida foram selecionadas.

No terceiro procedimento, foram trabalhados os dados de horas de insolação mensais de cada capital selecionada, totalizando 240 dados mensais referentes aos doze meses de cada um dos 20 anos selecionados. Entre esses meses, foram detectados os meses faltantes. Assim, dois quocientes foram calculados: a média mensal de horas de insolação (In mês) e a média mensal de horas de insolação diária (n). A primeira média representa as horas de insolação total média de um mês, enquanto a segunda média representa as horas de insolação de um dia de certo mês. A "In mês" advém do quociente entre a soma das horas de insolação de todos os meses no período de vinte anos e o total dos meses com dados disponíveis (Equação 1). Já a "n" é resultante da divisão entre a "In mês" do determinado mês e a quantidade exata de dias do respectivo mês (Equação 2). 


$$
\text { In mês }(\text { janeiro })=\frac{H I M\left(\frac{\text { janeiro }}{1997}\right)+\cdots+H I M\left(\frac{\text { janeiro }}{2016}\right)}{20-m f}
$$

Onde:

In mês: média mensal de horas de insolação;

Janeiro: exemplo de um mês;

HIM: horas de insolação mensal;

Janeiro/1997: exemplo mensal do primeiro ano de coleta;

Janeiro/2016: exemplo mensal do último e vigésimo ano de coleta;

20: período de coleta (anos);

Mf: meses faltantes.

$$
n(\text { janeiro })=\frac{\text { In mês }(\text { janeiro })}{31}
$$

Onde:

$\mathrm{n}$ = média mensal de horas de insolação diária;

Janeiro: exemplo de um mês;

In mês: média mensal de horas de insolação;

31: dias exatos do mês de janeiro.

Ressalva-se que os meses faltantes dos anos bissextos e não-bissextos foram devidamente separados. Logo, "In mês" e " $n$ " do mês de fevereiro foram obtidos das médias ponderadas das médias "In mês" e " $n$ " parciais (bissexto e não-bissexto) com os respectivos meses faltantes - como mostram as tabelas exemplificativas (Tabelas 2

\begin{tabular}{|c|c|c|c|c|c|c|}
\hline & Tipo de ano & $\begin{array}{c}\text { In mês parcial } \\
\text { (h mês) }\end{array}$ & Anos totais & $\begin{array}{c}\text { Anos } \\
\text { faltantes }\end{array}$ & $\begin{array}{c}\text { Anos } \\
\text { disponíveis }\end{array}$ & $\begin{array}{l}\text { In mês } \\
\text { (h mês) }\end{array}$ \\
\hline \multirow{2}{*}{ Fevereiro } & Não-bissexto & 200 & 28 & 7,14 & 14 & \multirow{2}{*}{213,16} \\
\hline & Bissexto & 250 & 29 & 8,62 & 5 & \\
\hline
\end{tabular}
e 3).

Fonte: As autoras.

\begin{tabular}{|c|c|c|c|c|c|c|}
\hline & Tipo de ano & $\begin{array}{c}\text { In mês parcial } \\
\text { (h mês) }\end{array}$ & $\begin{array}{c}\text { Quant. dias } \\
\text { exatos }\end{array}$ & $\begin{array}{l}\text { n parcial } \\
\text { (h dia) }\end{array}$ & $\begin{array}{c}\text { Anos } \\
\text { disponíveis }\end{array}$ & $\begin{array}{c}n \\
\text { (h dia) }\end{array}$ \\
\hline \multirow{2}{*}{ Fevereiro } & Não-bissexto & 200 & 28 & 7,14 & 14 & \multirow{2}{*}{7,53} \\
\hline & Bissexto & 250 & 29 & 8,62 & 5 & \\
\hline
\end{tabular}

Tabela 3 - Exemplo de obtenção da média mensal de horas de insolação diária ( $\mathrm{n}$ )

Fonte: As autoras.

No quarto procedimento, foram trabalhados os dados de horas de insolação diários de cada capital selecionada. A princípio, os dias faltantes foram detectados em um universo de cerca de 7300 dados diários por cidade. Dessa forma, foi possível calcular a média mensal da máxima de possibilidades de horas de insolação diária $(\mathrm{N})$ de cada cidade. Para isso, calculou-se a "N" de cada mês por meio da divisão do somatório de horas de insolação diária máxima daquele mês de todos os anos do período de coleta pela quantidade de dias máximos disponíveis (Equação 3). Com isso, dos cerca de 7300 dados diários por cidade foram selecionados 240 valores máximos (vinte valores para cada mês), resultando em 12 "N" (um para cada mês). Esses "valores máximos" 
correspondem ao "HIDM" da Equação 3. Os dias máximos faltantes ocorreram nos meses sem dados diários e nos meses com menos de metade dos dados diários.

$$
N(\text { janeiro })=\frac{\operatorname{HIMD}\left(\frac{\text { janeiro }}{1997}\right)+\cdots+H \operatorname{IMD}\left(\frac{\text { janeiro }}{2016}\right)}{20-d m f}
$$

Onde:

$\mathrm{N}$ = média das horas de insolação máxima;

Janeiro: exemplo de um mês;

$H I D M\left(\frac{m e ̂ s}{a n o}\right)$ : horas de insolação diária máxima no mês considerado de um dos anos de coleta;

1997: primeiro ano do período de coleta;

2016: vigésimo e último ano do período de coleta;

20: período de coleta (anos);

dmf: dias máximos faltantes.

No quinto procedimento, os dados resultantes das terceira e quarta etapas foram compilados em uma única tabela para encontrar a condição de céu de cada capital. Inicialmente, cada tabela foi estruturada com quatro colunas: "mês", "In mês", "n" e "N" - representando respectivamente: identificação do mês; horas de insolação total do mês; horas de insolação diária do mês e horas de insolação máxima do mês, sendo todos esses valores médios, por representarem um período maior que um ano. Em seguida, foram calculadas as razões do sol (RS) de cada mês em função da razão entre "n" e "N" (Equação 4). Com essa porcentagem resultante, pôde-se classificar a condição de céu como céu claro (o a 40\%), parcialmente encoberto (40 a 70\%) ou encoberto (70 a 100\%) (FERREIRA; SOUZA, 2006). Ao final dessa etapa, cada tabela possuía duas novas colunas: "RS" e "condição de céu".

$$
\mathrm{RS}=\frac{\mathrm{n}}{\mathrm{N}}
$$

Onde:

$$
\begin{aligned}
& \mathrm{RS}=\text { razão do sol; } \\
& \mathrm{n}=\text { média mensal de horas de insolação diária; } \\
& \mathrm{N}=\text { média das horas de insolação máxima; }
\end{aligned}
$$

Ao final do quinto procedimento, foram obtidas as condições de céu mensais de cada capital, encerrando-se a primeira etapa. Com base nesses resultados, o sexto procedimento consistiu na criação dos parâmetros de classificação dos quinze tipos de céu CIE. Para isso, foram realizados dois subprocedimentos relacionados com: (a) as porcentagens parciais de cada céu CIE por condição de céu; e (b) as faixas percentuais de cada céu CIE. No subprocedimento $6 a$, a faixa percentual de cada condição céu (FPCC) foi separada, segundo os parâmetros de Ferreira e Souza (2006). Para se obter a porcentagem parcial de cada condição de céu (PPCC), subtraiu-se a maior porcentagem da faixa percentual de cada céu pela menor (por exemplo, condição de céu B: 100\% - 60\% $=40 \%$ ). Essa porcentagem resultante (PPCC) foi dividida pela quantidade de céus CIE (QCC) da respectiva condição de céu, obtendo a porcentagem parcial de céu CIE (PPCIE) relativa a cada condição de céu (Tabela 4). 
Tabela 4 - Exemplo do subprocedimento 6a: obtenção da porcentagem parcial dos céus CIE por condição de céu

\begin{tabular}{cccccc}
\hline $\begin{array}{c}\text { Condição } \\
\text { de céu }\end{array}$ & $\begin{array}{c}\text { Faixa percentual de } \\
\text { condição de céu (FPCC) }\end{array}$ & $\begin{array}{c}\text { Porcentagem parcial de } \\
\text { condição de céu (PPCC) }\end{array}$ & $\begin{array}{c}\text { Quant. céus CIE por } \\
\text { condição de céu (QCC) }\end{array}$ & $\begin{array}{c}\text { Porcentagem parcial de } \\
\text { céu CIE por condição de } \\
\text { céu (PPCIE) }\end{array}$ \\
\hline B & $>60 \%$ & $a \leq 100 \%$ & $40 \%$ & 2 & $20 \%$ \\
\hline A & $0 \%$ a $\leq 60 \%$ & $60 \%$ & 2 & $30 \%$ \\
\hline
\end{tabular}

Fonte: As autoras.

A princípio no subprocedimento $6 \mathrm{~b}$ de classificação do céu $\mathrm{CIE}$, a primeira faixa da primeira condição de céu foi definida do $0 \%$ até o percentual referente à faixa percentual parcial de céu CIE por condição de céu (PPCIE). Nos exemplos desta metodologia, a faixa 1 da condição A foi do $0 \%$ até $30 \%$ (FPCIE, Tabela 5) visto que o PPCIE da condição A é $30 \%$ (PPCIE, Tabela 4). As demais faixas percentuais (FPCIE) foram definidas pela repetição do maior percentual do céu CIE anterior acrescido da porcentagem parcial do céu CIE para aquela condição de céu (PPCIE, Tabela 4). Nos exemplos, como a condição de céu A tem dois céus CIE (QCC, Tabela 4), o céu CIE 2 (ICIE) também possui PPCIE de 30\%. Assim, o céu CIE 2 ficou de 30,01\% a 60,00\%. O mesmo processo foi aplicado para os demais céus $\mathrm{CIE}$, acrescentando sempre o PPCIE referente àquela condição de céu - nos exemplos, os céus $\mathrm{CIE} 3$ e 4 foram acrescidos de $20 \%$, pois a condição de céu $A$ possui dois céus CIE (do 1 ao 2), assim como a B (céus CIE 3 e 4).

Tabela 5 - Exemplo do subprocedimento 6b: classificação céus CIE

\begin{tabular}{rrrr}
\hline \multicolumn{2}{c}{ Faixa percentual de céu CIE (FPCIE) } & Identificação céu CIE (ICIE) & \multirow{2}{*}{ Condição de céu } \\
\hline $80,01 \%$ & $-100,00 \%$ & 4 & \multirow{2}{*}{$\mathrm{B}$} \\
\hline $60,01 \%$ & $-80,00 \%$ & 3 & \multirow{2}{*}{$\mathrm{A}$} \\
\hline $30,01 \%$ & $-60,00 \%$ & 2 \\
\hline $0,00 \%$ & $-30,00 \%$ & 1 &
\end{tabular}

Fonte: As autoras.

Com o parâmetro de classificação dos céus CIE estabelecido, estabeleceu-se, na sétima etapa, os céus CIE mensais característicos de cada capital, completando as tabelas geradas ao término da quinta etapa com a coluna "tipo de céu CIE". Na oitava etapa, os resultados da sétima etapa foram ratificados por meio de comparação entre os céus CIE mensais encontrados para cada capital com os dados de nebulosidade disponibilizados pelo INMET (1997-2016b) para o mesmo ínterim. Essa análise foi realizada por meio de gráfico único por capital cruzando os céus $\mathrm{CIE}$ e os valores de nebulosidade. Os gráficos das capitais foram expostos todos em uma única tabela.

\section{Resultados}

Os resultados do artigo são apresentados nas seguintes etapas:

1. Cenário geral das estações e seleção das capitais;

2. Classificação dos céus CIE;

3. Condições e tipo de céu de cada capital.

Cenário Geral das Estações e Seleção das Capitais

Apresenta-se na Tabela 6 a situação geral de cada capital do Centro-Sul do Brasil, com a categorização de informações concernentes à respectiva estação meteorológica e à disponibilidade dos dados de horas de insolação diárias e mensais. Com essa compilação de dados, foi possível excluir as capitais que não possuíam os dados desejados delimitando assim o recorte a ser trabalhado. Conforme destacado na Tabela 6, foram identificadas as seguintes situações:

a) Campo Grande (em marrom) não possui estação meteorológica; 
b) Goiânia e Rio de Janeiro (em azul) não possuem dados de horas de insolação diárias e mensais no período selecionado (jan./1997 a dez./2016);

c) Das capitais com dados de horas de insolação, apenas Cuiabá e São Paulo (em verde) possuem um período menor que o selecionado para coleta, com um início de disponibilidade dos dados um pouco posterior à data inicial estipulada.

Tabela 6 - Estações meteorológicas das capitais do Centro-Sul do país e período de disponibilidade de dados de horas de insolação

\begin{tabular}{|c|c|c|c|c|c|c|c|c|}
\hline \multirow{2}{*}{$\begin{array}{c}\text { Estação } \\
\text { OMM } \\
83361\end{array}$} & \multirow{2}{*}{$\frac{\text { Capital }}{\text { Cuiabá }}$} & \multirow{2}{*}{$\begin{array}{c}\begin{array}{c}\text { Unidade } \\
\text { federativa }\end{array} \\
\mathrm{MT}\end{array}$} & \multirow{2}{*}{$\begin{array}{c}\begin{array}{c}\text { Latitude } \\
\text { (graus) }\end{array} \\
-15,61\end{array}$} & \multirow{2}{*}{$\begin{array}{c}\begin{array}{c}\text { Longitude } \\
\text { (graus) }\end{array} \\
-56,10\end{array}$} & \multirow{2}{*}{$\begin{array}{c}\begin{array}{c}\text { Altitude } \\
\text { (m) }\end{array} \\
145,00\end{array}$} & \multirow{2}{*}{$\begin{array}{c}\begin{array}{c}\text { Início da } \\
\text { operação }\end{array} \\
\text { 01/01/1911 }\end{array}$} & \multicolumn{2}{|c|}{$\begin{array}{l}\text { Período dos dados } \\
\text { disponíveis }\end{array}$} \\
\hline & & & & & & & jan/98 & 2016 \\
\hline \multirow[t]{2}{*}{83423} & Goiânia & GO & $-16,66$ & $-49,25$ & 741,48 & 11/07/1937 & $x$ & $x$ \\
\hline & C. Grande & MS & & & & & & \\
\hline 83377 & Brasília & DF & $-15,78$ & $-47,92$ & 1159,54 & $12 / 09 / 1961$ & 1997 & 2016 \\
\hline 83587 & B. Horizonte & MG & $-19,93$ & $-45,93$ & 915,00 & 03/03/1910 & 1997 & 2016 \\
\hline 83648 & Vitória & ES & $-20,31$ & $-40,31$ & 36,20 & $20 / 11 / 1923$ & 1997 & 2016 \\
\hline 83743 & R. Janeiro & RJ & $-22,89$ & $-43,18$ & 11,10 & $01 / 01 / 1917$ & $x$ & $x$ \\
\hline 83781 & São Paulo & SP & $-23,50$ & $-46,61$ & 792,06 & $01 / 12 / 1945$ & nov/97 & 2016 \\
\hline 83842 & Curitiba & PR & $-25,43$ & $-49,26$ & 923,50 & $01 / 01 / 1911$ & 1997 & 2016 \\
\hline 83897 & Florianópolis & SC & $-27,58$ & $-48,56$ & 1,84 & $01 / 12 / 1921$ & 1997 & 2016 \\
\hline 83967 & Porto Alegre & RS & $-30,05$ & $-51,16$ & 46,97 & 09/12/1909 & 1997 & 2016 \\
\hline
\end{tabular}

Fonte: As autoras. Retirado de: INMET (1997-2016a).

Com essas apurações, as capitais Goiânia, Campo Grande e Rio de Janeiro foram excluídas do escopo da pesquisa por falta dos dados de horas de insolação. Cuiabá, São Paulo e as outras capitais form mantidas por possuírem um período de dados disponíveis superior a cinco anos considerando os dados faltantes pontuais dentro do período disponível (WU et al., 2013). Consequentemente, as capitais do estudo foram limitadas a: Cuiabá, Brasília, Belo Horizonte, Vitória, São Paulo, Curitiba, Florianópolis e Porto Alegre.

\section{Classificação dos Céus CIE}

Apresenta-se a seguir uma classificação simplificada dos céus CIE, com finalidade específica de servir como dado de entrada para programas de simulação de iluminação natural com céu estático de cidades que não possuam esse tipo de informação. $\mathrm{Na}$ Tabela 7, são expostas as porcentagens parciais de cada céu CIE de acordo com a respectiva condição de céu, obtidas da razão entre a porcentagem parcial de cada condição de céu pela quantidade de céus CIE. Na Tabela 8, apresentam-se as faixas percentuais de cada céu CIE, já com os respectivos percentuais por tipo de céu acrescentados.

\section{Condições e Tipo de Céu de cada Capital}

A seguir são apresentados as condições e tipos de céu CIE mensais encontrados como característicos de cada capital do Centro-Sul do país que tenha dados de horas de insolação do INMET(1997-2016a) (Tabelas 9 a 16). Também são expostos os dados meteorológicos médios e percentuais que resultaram nos céus obtidos. Cada tabela considera as seguintes nomenclaturas:

- In mês: média mensal de horas de insolação;

- $\quad$ n: média mensal de horas de insolação diária;

- $\quad$ N: média mensal da máxima de possibilidades de horas de insolação diária;

- RS: razão do sol.

Os meses de junho e dezembro foram destacados por serem os recomendados pela NBR 15.215-4 (ABNT, 2005b) para verificação de iluminância do local, uma vez que 
MICHEL, Mariana Vallory; LARANJA, Andréa Coelho.

Condições e tipos de céu para simulações de iluminação natural com céu estático

abrangem os solstícios de inverno e verão, respectivamente. É importante salientar que, ainda que a recomendação normativa seja de verificar a iluminância nos solstícios, cada projeto possui suas especificidades. Por isso, foram apresentados os resultados de todos os meses, dando liberdade de utilização de acordo com as peculiaridades do projeto que necessite desses dados.

Tabela 7 - Porcentagem parcial de cada céu CIE por condição de céu

\begin{tabular}{|c|c|c|c|c|c|c|c|}
\hline Condição de céu & & $\begin{array}{l}\text { Faixa } \\
\text { conc }\end{array}$ & oer & $\begin{array}{l}\text { centual de } \\
\text { de céu* }\end{array}$ & $\begin{array}{l}\text { Porcentagem parcial } \\
\text { de condição de céu }\end{array}$ & $\begin{array}{l}\text { Quant. céus CIE por } \\
\text { condição de céu }\end{array}$ & $\begin{array}{l}\text { Porcentagem parcial de } \\
\text { céu CIE por cond. de céu }\end{array}$ \\
\hline Claro & $>$ & $70 \%$ & $\mathrm{a}$ & $\leq 100 \%$ & $30 \%$ & 5 & $6 \%$ \\
\hline Parcialmente encoberto & $>$ & $40 \%$ & $\mathrm{a}$ & $\leq 70 \%$ & $30 \%$ & 5 & $6 \%$ \\
\hline Encoberto & & $0 \%$ & $\mathrm{a}$ & $\leq 40 \%$ & $40 \%$ & 5 & $8 \%$ \\
\hline
\end{tabular}

Fonte: As autoras. Retirado de Ferreira e Souza (2006).

Tabela 8 - Classificação simplificada dos céus CIE

\begin{tabular}{|c|c|c|c|}
\hline \multicolumn{2}{|c|}{ Faixa percentual de céu CIE } & \multirow{2}{*}{$\begin{array}{c}\begin{array}{c}\text { Tipo de céu } \\
\text { CIE }\end{array} \\
15 \\
\end{array}$} & \multirow[t]{2}{*}{ Condição de céu } \\
\hline $94,01 \%$ & $-100,00 \%$ & & \\
\hline $88,01 \%$ & $-94,00 \%$ & 14 & \multirow{4}{*}{ Claro } \\
\hline $82,01 \%$ & $-\quad 88,00 \%$ & 13 & \\
\hline $76,01 \%$ & $-\quad 82,00 \%$ & 12 & \\
\hline $70,01 \%$ & - $76,00 \%$ & 11 & \\
\hline $64,01 \%$ & - $\quad 70,00 \%$ & 10 & \multirow{5}{*}{ Parcialmente encoberto } \\
\hline $58,01 \%$ & $-\quad 64,00 \%$ & 9 & \\
\hline $52,01 \%$ & $-\quad 58,00 \%$ & 8 & \\
\hline $46,01 \%$ & $-\quad 52,00 \%$ & 7 & \\
\hline $40,01 \%$ & $-\quad 46,00 \%$ & 6 & \\
\hline $32,01 \%$ & $-\quad 40,00 \%$ & 5 & \multirow{5}{*}{ Encoberto } \\
\hline $24,01 \%$ & $-\quad 32,00 \%$ & 4 & \\
\hline $16,01 \%$ & $-\quad 24,00 \%$ & 3 & \\
\hline $8,01 \%$ & $-16,00 \%$ & 2 & \\
\hline $0,00 \%$ & $-\quad 8,00 \%$ & 1 & \\
\hline
\end{tabular}

Tabela 9 - Cuiabá: Horas de Insolação, Razão do Sol e Céus

\begin{tabular}{cccccc}
\hline Mês & In. Mês & $\mathrm{n}^{1}$ & $\mathrm{~N}^{1}$ & $\mathrm{RS}$ & \multicolumn{2}{c}{ Condição de céu } \\
\hline Janeiro & 151,81 & 4,90 & 10,77 & $45,48 \%$ & Parcialmente encoberto \\
\hline Fevereiro & 139,73 & 4,97 & 10,52 & $47,23 \%$ & Parcialmente encoberto \\
\hline Março & 175,22 & 5,65 & 10,49 & $53,89 \%$ & Parcialmente encoberto \\
\hline Abril & 202,33 & 6,74 & 10,49 & $64,27 \%$ & Parcialmente encoberto \\
\hline Maio & 205,98 & 6,64 & 10,12 & $65,67 \%$ & Parcialmente encoberto \\
\hline Junho & 199,10 & 6,64 & 9,39 & $70,65 \%$ & Claro \\
\hline Julho & 230,75 & 7,44 & 9,99 & $74,52 \%$ & Claro \\
\hline Agosto & 241,27 & 7,78 & 10,24 & $75,97 \%$ & Claro \\
\hline Setembro & 175,29 & 5,84 & 10,27 & $56,91 \%$ & Parcialmente encoberto \\
\hline Outubro & 180,08 & 5,81 & 10,73 & $54,15 \%$ & Parcialmente encoberto \\
\hline Novembro & 175,03 & 5,83 & 11,28 & $51,73 \%$ & Parcialmente encoberto \\
\hline Dezembro & 142,04 & 4,58 & 10,36 & $44,22 \%$ & Parcialmente encoberto \\
\hline
\end{tabular}

Nota: quantidade de dados faltantes = 36. Fonte: As autoras, baseado em INMET (1997-2016a). 
MICHEL, Mariana Vallory; LARANJA, Andréa Coelho.

Condições e tipos de céu para simulações de iluminação natural com céu estático

Tabela 10 - Brasília: Horas de Insolação, Razão do Sol e Céus

\begin{tabular}{ccccccc}
\hline Mês & In. Mês & $\mathrm{n}$ & $\mathrm{N}$ & $\mathrm{RS}$ & Condição de céu \\
\hline Janeiro & 155,76 & 5,02 & 10,84 & $46,35 \%$ & Parcialmente encoberto \\
\hline Fevereiro & 168,52 & 5,96 & 10,94 & $54,48 \%$ & Parcialmente encoberto \\
\hline Março & 170,93 & 5,51 & 10,23 & $53,90 \%$ & Parcialmente encoberto & 8 \\
\hline Abril & 208,60 & 6,95 & 10,31 & $67,44 \%$ & Parcialmente encoberto & Claro \\
\hline Maio & 239,70 & 7,73 & 10,03 & $77,09 \%$ & Claro & 12 \\
\hline Junho & 245,98 & 8,20 & 9,64 & $85,06 \%$ & Claro & Claro \\
\hline Julho & 268,14 & 8,65 & 9,88 & $87,55 \%$ & Claro \\
\hline Agosto & 280,56 & 9,05 & 10,49 & $86,27 \%$ & 13 \\
\hline Setembro & 229,63 & 7,65 & 10,50 & $72,90 \%$ & 13 \\
\hline Outubro & 194,48 & 6,27 & 10,76 & $58,30 \%$ & Parcialmente encoberto \\
\hline Novembro & 138,63 & 4,62 & 10,54 & $43,84 \%$ & Parcialmente encoberto \\
\hline Dezembro & 147,95 & 4,77 & 11,08 & $43,07 \%$ & Parcialmente encoberto
\end{tabular}

Nota: quantidade de dados faltantes = 0. Fonte: As autoras, baseado em INMET (1997-2016a).

Tabela 11 - Belo Horizonte: Horas de Insolação, Razão do Sol e Céus

\begin{tabular}{|c|c|c|c|c|c|c|}
\hline Mês & In. Mês & $\mathrm{n}$ & $\mathrm{N}$ & RS & Condição de céu & Tipo de céu CIE \\
\hline Janeiro & 180,49 & 5,82 & 11,54 & $50,47 \%$ & Parcialmente encoberto & 7 \\
\hline Fevereiro & 198,35 & 7,02 & 11,18 & $62,80 \%$ & Parcialmente encoberto & 9 \\
\hline Março & 189,69 & 6,12 & 10,28 & $59,55 \%$ & Parcialmente encoberto & 9 \\
\hline Abril & 204,36 & 6,81 & 9,53 & $71,52 \%$ & Claro & 11 \\
\hline Maio & 215,79 & 6,96 & 9,28 & $75,05 \%$ & Claro & 11 \\
\hline Junho & 222,70 & 7,42 & 9,14 & $81,22 \%$ & Claro & 12 \\
\hline Julho & 233,09 & 7,52 & 9,05 & $83,08 \%$ & Claro & 13 \\
\hline Agosto & 250,41 & 8,08 & 9,61 & $84,10 \%$ & Claro & 13 \\
\hline Setembro & 215,60 & 7,19 & 10,12 & $71,05 \%$ & Claro & 11 \\
\hline Outubro & 208,68 & 6,73 & 10,90 & $61,76 \%$ & Parcialmente encoberto & 9 \\
\hline Novembro & 163,88 & 5,46 & 11,40 & $47,94 \%$ & Parcialmente encoberto & 7 \\
\hline Dezembro & 163,48 & 5,27 & 11,35 & $46,46 \%$ & Parcialmente encoberto & 7 \\
\hline
\end{tabular}

Nota: quantidade de dados faltantes = 3. Fonte: As autoras, baseado em INMET (1997-2016a).

Tabela 12 - Vitória: Horas de Insolação, Razão do Sol e Céus

\begin{tabular}{cccccc}
\hline Mês & In. Mês & $\mathrm{n}$ & $\mathrm{N}$ & $\mathrm{RS}$ & \multicolumn{2}{c}{ Condição de céu } \\
\hline Janeiro & 206,03 & 6,65 & 10,84 & $61,30 \%$ & Parcialmente encoberto \\
\hline Fevereiro & 225,17 & 7,97 & 10,75 & $74,17 \%$ & Claro \\
\hline Março & 204,76 & 6,61 & 10,12 & $65,26 \%$ & Parcialmente encoberto \\
\hline Abril & 190,47 & 6,35 & 9,50 & $66,87 \%$ & Parcialmente encoberto \\
\hline Maio & 187,29 & 6,04 & 9,45 & $63,93 \%$ & Parcialmente encoberto \\
\hline Junho & 182,27 & 6,08 & 9,15 & $66,40 \%$ & Parcialmente encoberto \\
\hline Julho & 187,43 & 6,05 & 9,23 & $65,49 \%$ & Parcialmente encoberto \\
\hline Agosto & 205,82 & 6,64 & 9,51 & $69,81 \%$ & Parcialmente encoberto \\
\hline Setembro & 170,15 & 5,67 & 9,82 & $57,78 \%$ & Parcialmente encoberto \\
\hline Outubro & 166,39 & 5,37 & 10,39 & $51,64 \%$ & Parcialmente encoberto \\
\hline Novembro & 142,07 & 4,74 & 10,46 & $45,26 \%$ & Parcialmente encoberto \\
\hline Dezembro & 169,79 & 5,48 & 10,65 & $51,44 \%$ & Parcialmente encoberto
\end{tabular}

Nota: quantidade de dados faltantes = 11. Fonte: As autoras, baseado em INMET (1997-2016a).

Tabela 13 - São Paulo: Horas de Insolação, Razão do Sol e Céus

\begin{tabular}{cccccc}
\hline Mês & In. Mês & $\mathrm{n}$ & $\mathrm{N}$ & $\mathrm{RS}$ & \multicolumn{2}{c}{ Condição de céu } \\
\hline Janeiro & 119,93 & 3,87 & 11,37 & $34,01 \%$ & Tipo de céu CIE \\
\hline Fevereiro & 135,45 & 4,80 & 11,43 & $42,02 \%$ & Parcialmente encoberto \\
\hline Março & 142,03 & 4,58 & 10,58 & $43,30 \%$ & Parcialmente encoberto \\
\hline Abril & 149,10 & 4,97 & 10,21 & $48,67 \%$ & Parcialmente encoberto \\
\hline Maio & 129,69 & 4,18 & 9,55 & $43,81 \%$ & Parcialmente encoberto \\
\hline Junho & 123,39 & 4,11 & 8,27 & $49,75 \%$ & Parcialmente encoberto \\
\hline Julho & 136,83 & 4,41 & 9,19 & $48,01 \%$ & Parcialmente encoberto \\
\hline Agosto & 161,03 & 5,19 & 10,19 & $50,96 \%$ & Parcialmente encoberto \\
\hline Setembro & 133,36 & 4,45 & 10,47 & $42,47 \%$ & Parcialmente encoberto \\
\hline Outubro & 136,22 & 4,39 & 10,91 & $40,29 \%$ & Parcialmente encoberto \\
\hline Novembro & 128,47 & 4,28 & 11,53 & $37,14 \%$ & Encoberto \\
\hline Dezembro & 137,60 & 4,44 & 11,37 & $39,04 \%$ & 6 \\
\hline
\end{tabular}

Nota: quantidade de dados faltantes = 26. Fonte: As autoras, baseado em INMET (1997-2016a) 
MICHEL, Mariana Vallory; LARANJA, Andréa Coelho.

Condições e tipos de céu para simulações de iluminação natural com céu estático

Tabela 14 - Curitiba: Horas de Insolação, Razão do Sol e Céus

\begin{tabular}{cccccc}
\hline Mês & In. Mês & $\mathrm{n}$ & $\mathrm{N}$ & $\mathrm{RS}$ & Condição de céu \\
\hline Janeiro & 155,64 & 5,02 & 11,27 & $44,53 \%$ & Parcialmente encoberto de céu CIE \\
\hline Fevereiro & 153,24 & 5,42 & 11,02 & $49,18 \%$ & Parcialmente encoberto \\
\hline Março & 168,78 & 5,44 & 10,72 & $50,81 \%$ & Parcialmente encoberto \\
\hline Abril & 157,18 & 5,24 & 10,16 & $51,58 \%$ & Parcialmente encoberto \\
\hline Maio & 146,34 & 4,72 & 9,76 & $48,35 \%$ & Parcialmente encoberto \\
\hline Junho & 140,09 & 4,67 & 9,26 & $50,44 \%$ & Parcialmente encoberto \\
\hline Julho & 158,07 & 5,10 & 9,75 & $52,28 \%$ & Parcialmente encoberto \\
\hline Agosto & 185,76 & 5,99 & 10,24 & $58,54 \%$ & Parcialmente encoberto \\
\hline Setembro & 141,02 & 4,70 & 10,55 & $44,54 \%$ & Parcialmente encoberto \\
\hline Outubro & 133,95 & 4,32 & 11,17 & $38,67 \%$ & Encoberto \\
\hline Novembro & 152,86 & 5,10 & 11,67 & $43,67 \%$ & Parcialmente encoberto \\
\hline Dezembro & 157,49 & 5,08 & 11,72 & $43,34 \%$ & Parcialmente encoberto
\end{tabular}

Nota: quantidade de dados faltantes $=12$. Fonte: As autoras, baseado em INMET (1997-2016a).

Tabela 15 - Florianópolis: Horas de Insolação, Razão do Sol e Céus

\begin{tabular}{cccccc}
\hline Mês & In. Mês & $\mathrm{n}$ & $\mathrm{N}$ & $\mathrm{RS}$ & \multicolumn{2}{c}{ Condição de céu } \\
\hline Janeiro & 190,34 & 6,14 & 11,97 & $51,29 \%$ & Parcialmente encoberto \\
\hline Fevereiro & 176,02 & 6,24 & 11,57 & $53,94 \%$ & Parcialmente encoberto \\
\hline Março & 194,77 & 6,28 & 10,99 & $57,17 \%$ & Parcialmente encoberto \\
\hline Abril & 175,33 & 5,84 & 10,41 & $56,14 \%$ & Parcialmente encoberto \\
\hline Maio & 172,01 & 5,55 & 9,93 & $55,88 \%$ & Parcialmente encoberto \\
\hline Junho & 152,16 & 5,07 & 9,46 & $53,61 \%$ & Parcialmente encoberto \\
\hline Julho & 156,17 & 5,04 & 9,73 & $51,78 \%$ & Parcialmente encoberto \\
\hline Agosto & 171,19 & 5,52 & 10,24 & $53,93 \%$ & Parcialmente encoberto \\
\hline Setembro & 143,21 & 4,77 & 10,58 & $45,12 \%$ & Parcialmente encoberto \\
\hline Outubro & 138,50 & 4,47 & 11,21 & $39,85 \%$ & Encoberto \\
\hline Novembro & 172,82 & 5,76 & 12,12 & $47,53 \%$ & Parcialmente encoberto \\
\hline Dezembro & 184,28 & 5,94 & 11,93 & $49,83 \%$ & Parcialmente encoberto \\
\hline
\end{tabular}

Nota: quantidade de dados faltantes = 24. Fonte: As autoras, baseado em INMET (1997-2016a)

Tabela 16 - Porto Alegre: Horas de Insolação, Razão do Sol e Céus

\begin{tabular}{cccccc}
\hline Mês & In. Mês & $\mathrm{n}$ & $\mathrm{N}$ & $\mathrm{RS}$ & \multicolumn{2}{c}{ Condição de céu } \\
\hline Janeiro & 240,02 & 7,74 & 12,15 & $63,74 \%$ & Parcialmente encoberto \\
\hline Fevereiro & 205,67 & 7,30 & 11,67 & $62,50 \%$ & Parcialmente encoberto \\
\hline Março & 205,66 & 6,63 & 10,55 & $62,90 \%$ & Parcialmente encoberto \\
\hline Abril & 166,59 & 5,55 & 9,83 & $56,48 \%$ & Parcialmente encoberto \\
\hline Maio & 141,59 & 4,57 & 8,24 & $55,42 \%$ & Parcialmente encoberto \\
\hline Junho & 118,63 & 3,95 & 7,99 & $49,49 \%$ & Parcialmente encoberto \\
\hline Julho & 136,30 & 4,40 & 8,05 & $54,64 \%$ & Parcialmente encoberto \\
\hline Agosto & 146,80 & 4,74 & 9,39 & $50,41 \%$ & Parcialmente encoberto \\
\hline Setembro & 146,27 & 4,88 & 10,43 & $46,74 \%$ & Parcialmente encoberto \\
\hline Outubro & 178,73 & 5,77 & 11,57 & $49,81 \%$ & Parcialmente encoberto \\
\hline Novembro & 219,95 & 7,33 & 12,10 & $60,59 \%$ & Parcialmente encoberto \\
\hline Dezembro & 235,12 & 7,58 & 12,25 & $61,93 \%$ & Parcialmente encoberto \\
\hline
\end{tabular}

Nota: quantidade de dados faltantes = 13. Fonte: As autoras, baseado em INMET (1997-2016a).

\section{Ratificação dos resultados}

A ratificação dos resultados da pesquisa pode ser verificada nas comparações gráficas entre os céus CIE encontrados com base nas horas de insolação e os dados mensais de nebulosidade disponibilizados pelo INMET (1997-2016b) para cada capital estudada (Figuras 1, 2 e 3). De modo geral, percebe-se uma real proporcionalidade inversa entre os dados de nebulosidade e de horas de sol na caracterização de céus, como defendido por Goulart (1993). Essa situação pode ser vista nas Figuras 1, 2 e 3, que mostra que quanto menos nebulosidade, maior tende a ser o céu CIE.

Nota-se, todavia, alguns resultados pontuais de algumas capitais em que o comportamento do céu não corresponde à reprodução inversa da nebulosidade, 
MICHEL, Mariana Vallory; LARANJA, Andréa Coelho.

Condições e tipos de céu para simulações de iluminação natural com céu estático

revelando fragilidades da simplificação do método de tratamento dos dados. Ressaltase, entretanto, que os casos não atendidos são minorias, não são muito acentuados e não comprometem a finalidade dos resultados de céu CIE: dado de entrada em programas de simulação de iluminação natural com céu estático para projetos que não exijam alta precisão de resultados. Ratifica-se, pois, o método para obtenção dos céus $\mathrm{CIE}$ empregado para a finalidade do artigo, principalmente pelo fato dos meses recomendados pela NBR 15.215-4 (2005b) possuírem dados coerentes na inversão dos dados - até mesmo para o caso de São Paulo, onde há o ponto de maior nãocorrespondência (agosto). Observa-se que este caso se refere ao céu CIE 5, que é um dos céus que possui grupo de indicatriz não proporcional ao aumento do número do céu CIE e que é o único céu CIE pertencente à condição de céu encoberto - que é característico de um céu mais uniforme (ABNT, 2005a).

Figura 1 - Céu CIE (linha azul) x Nebulosidade (linha cinza) das cidades do Centro Oeste simuladas
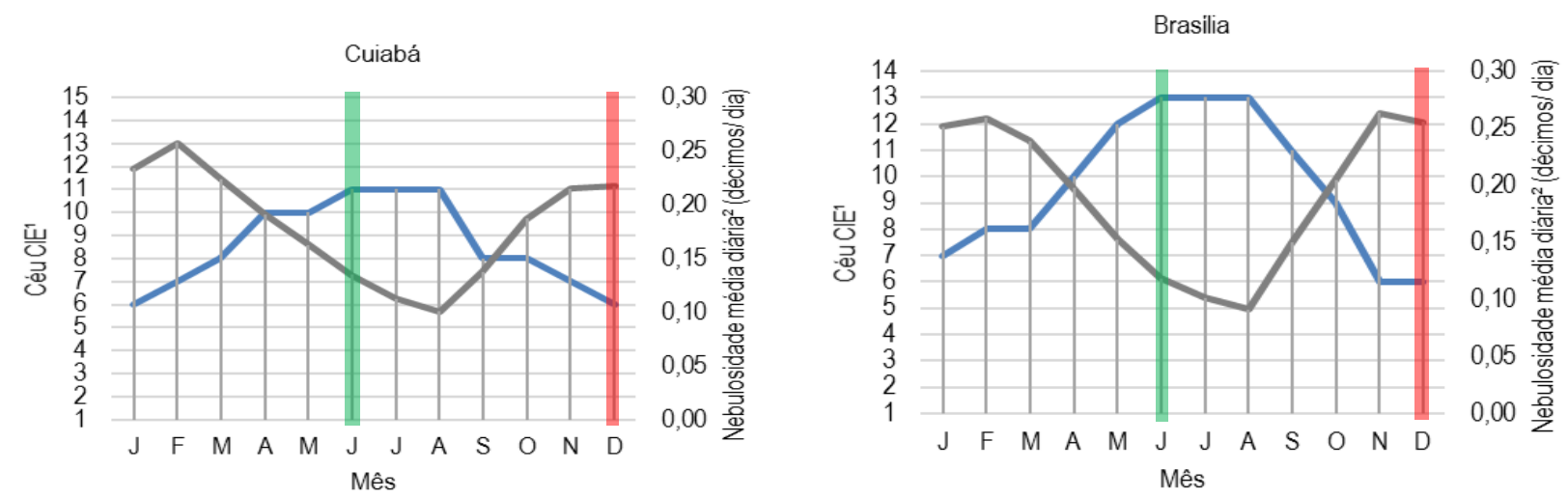

Nota: Destaque dos meses de solstícios de inverno (verde) e verão (vermelho). Fonte: As autoras.

Figura 2 - Céu CIE (linha azul) x Nebulosidade (linha cinza) das cidades do Sudeste simuladas
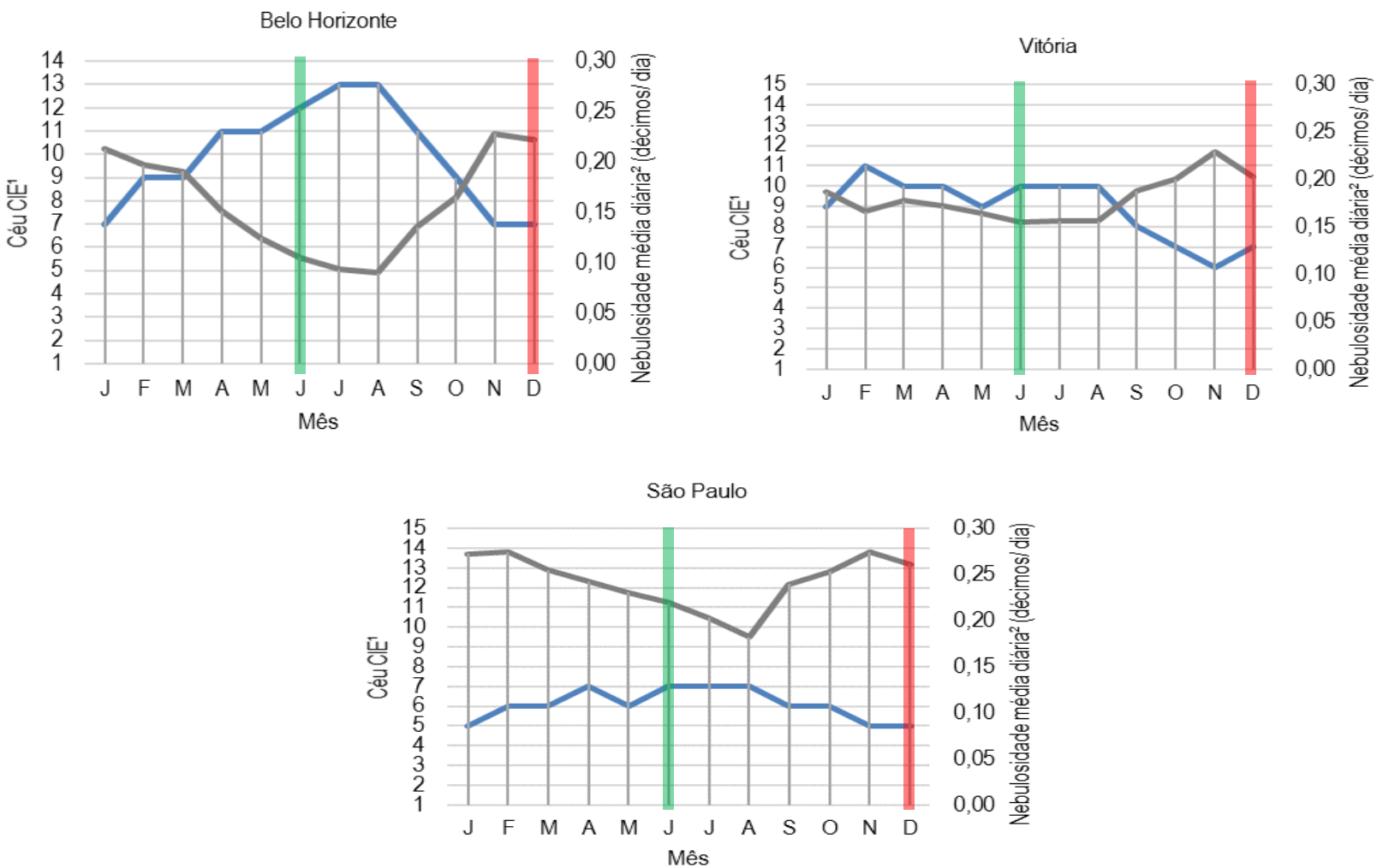

Nota: Destaque dos meses de solstícios de inverno (verde) e verão (vermelho). Fonte: As autoras. 
Figura 3 - Céu CIE (linha azul) x Nebulosidade (linha cinza) das cidades do Sul simuladas
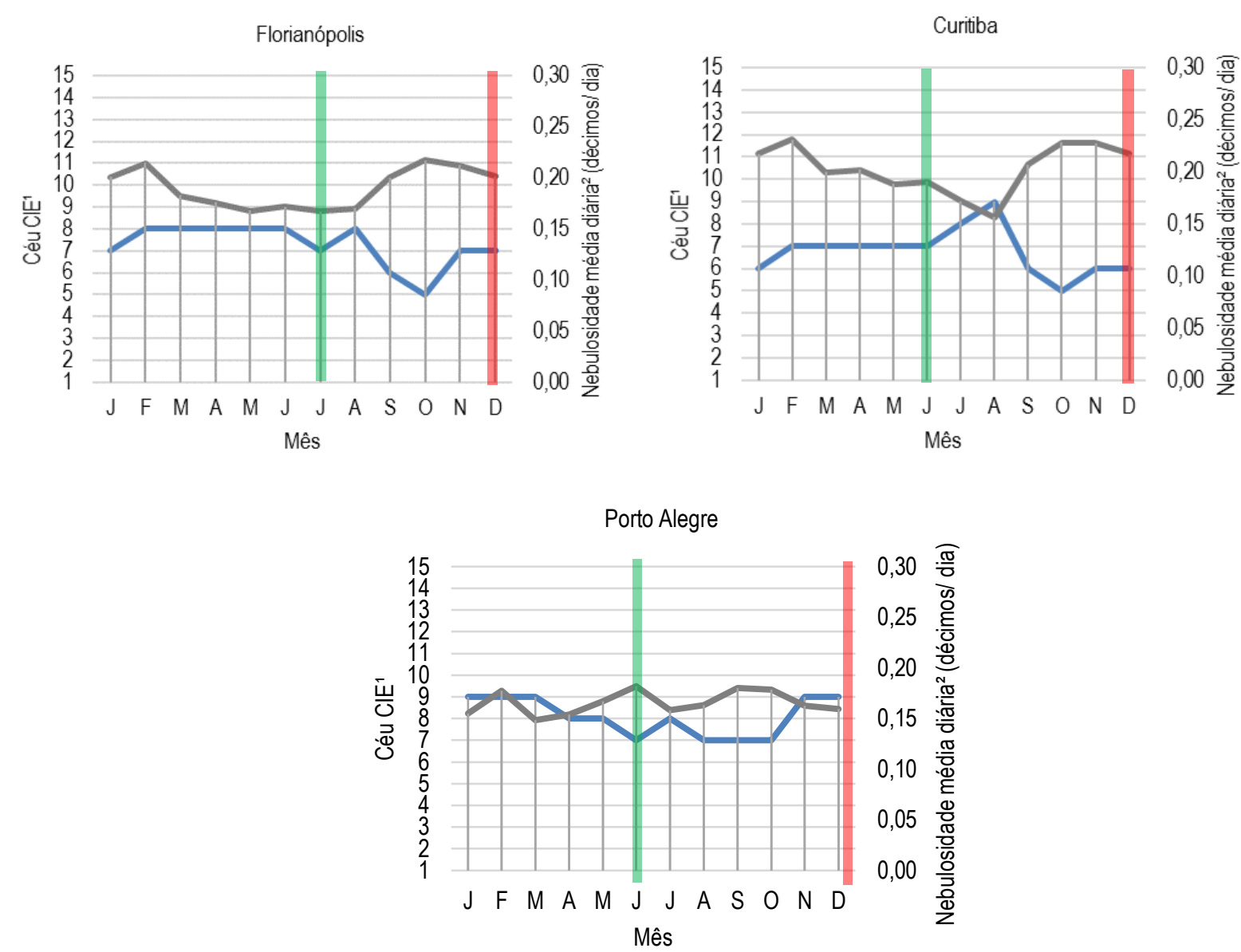

Nota: Destaque dos meses de solstícios de inverno (verde) e verão (vermelho). Fonte: As autoras.

\section{Conclusão}

Esta pesquisa pôde definir as condições de céu e céus CIE característicos de capitais brasileiras como opções simplificadas de dado de entrada em programas de simulação de iluminação natural com céu estático para projetos que não exijam alta precisão nos resultados. O campo de abrangência se restringiu às capitais brasileiras do Centro-Sul com dados de horas de insolação diários e mensais obtidos nas estações do INMET no intervalo de 1997-2016: Cuiabá, Brasília, Belo Horizonte, Vitória, São Paulo, Curitiba, Florianópolis e Porto Alegre. A metodologia pode ser estendida a qualquer cidade do país por meio de dados de horas de insolação de outras estações meteorológicas e por meio de medição visual com algum tipo de instrumento (como relógio) que possibilite que o pesquisador possa medir as horas de aparição do sol para as cidades sem estações. Sobre este, ressalva-se que o método visual, ainda que não seja o método mais recomendado, representa uma opção de obtenção de dados para caracterização de céu aplicável a inúmeras cidades no Brasil que não possuem estações meteorológicas segundo a metodologia apresentada neste artigo.

Os resultados encontrados para a condição de céu se basearam em uma metodologia simplificada já consolidada no meio acadêmico e já testada para a realidade brasileira. Já os resultados encontrados para os tipos de céu CIE basearam-se em um método proposto no presente artigo, que considerou uma correlação simplificada entre a classificação dos céus CIE e as horas de insolação - quanto maior a quantidade de horas de insolação, maior o céu CIE. 
Ao comparar os resultados dos tipos de céu CIE, obtidos com base nas horas de insolação, com os dados de nebulosidade, de forma a verificar as possíveis falhas da simplificação desse método, verificou-se, de modo geral, a ratificação da relação esperada, pois ambos se mostraram inversamente proporcionais. Desta forma, os céus $\mathrm{CIE}$ e as condições de céu resultantes do método proposto foram validados para as capitais estudadas. Observa-se que a etapa de obtenção do céu CIE precisa ser melhor verificada para os céus pertencentes à condição de céu encoberto, principalmente para os céus 3 e 5 , que possuem indicatriz não proporcional ao aumento do número do céu CIE.

Dessa forma, a presente pesquisa possibilita que profissionais e acadêmicos da área tenham um parâmetro simplificado para seleção de céu típico das capitais abordadas para solstícios de inverno e verão, conforme previsto na NBR 15.215-4 (ABNT, 2005b). Atenta-se que, para projetos que exijam alta precisão, sejam utilizados métodos mais complexos, que envolvam mais variáveis meteorológicas ou que se aprofundem na validação dos resultados, para suprir limitações da simplificação do método deste artigo. Além disso, aponta-se que o método proposto, passível de ser replicado, permite novas pesquisas para descoberta de céus de outras cidades - a destacar as demais capitais brasileiras não contempladas no recorte deste artigo.

\section{Agradecimentos}

O presente trabalho foi realizado com o apoio da Coordenação de Aperfeiçoamento de Pessoal do Nível Superior Brasil (CAPES).

\section{Notas}

(1) INMET - INSTITUTO NACIONAL DE METEOROLOGIA. Estações e dados. BPMED - Dados históricos. Banco de Dados Meteorológicos para Ensino e Pesquisa. http://www.inmet.gov.br/portal/index.php?r=bdmep/bdmep.

\section{Referências}

ABNT - ASSOCIAÇÃO BRASILEIRA DE NORMAS TÉCNICAS. NBR 15.215: lluminação natural - Parte 2: Procedimento de cálculo para a estimativa da disponibilidade de luz natural. Rio de Janeiro, $2005 a$.

ABNT - ASSOCIAÇÃO BRASILEIRA DE NORMAS TÉCNICAS. NBR 15.215: Iluminação natural - Parte 4: Verificação experimental das condições de iluminação interna de edificações - Método de medição. Rio de Janeiro, 2005b.

ALSHAIBANI, K. A. Classification Standard Skies: The use of horizontal sky illuminance. Renewable and Sustainable Energy Reviews, Great Britain, v. 73, p. 387-392, jan. 2017. DOI: https://doi.org/10.1016/j.rser.2017.01.116

BAKIRCI, K. Models of solar radiation with hours of bright sunshine. Renewable and Sustainable Energy Reviews, Great Britain, v. 13, p. 2580-2588, jul. 2009. DOI: https://doi.org/10.1016/j.rser.2009.07.011

BESHARAT, F.; DEHGHAN, A. A.; FAGHIH, A. R. Empirical models for estimating global solar radiation: A review and case study. Renewable and Sustainable Energy Reviews, Great Britain, v. 21, p. 798-821, mar. 2013. DOI:

https://doi.org/10.1016/j.rser.2012.12.043

BRASIL. Ministério do Desenvolvimento, Indústria e Comércio Exterior. Instituto Nacional de Metrologia, Qualidade e Tecnologia (INMETRO). Portaria n.18, de 2012. Manual para Aplicação do RTQ-R, Brasília, DF, v. 1, 202 p., jan. 2012. Disponível em:

http://www.pbeedifica.com.br/sites/default/files/projetos/etiquetagem/residencial/downloads/Manual_de_aplica\%C 3\%A7\%C3\%A30_do_\%20RTQ-R-v01.pdf. Acesso em: 04 ago. 2017.

CABÚS, R. Validação do programa TropLux. In: ENCONTRO NACIONAL E LATINO-AMERICANO DE CONFORTO NO AMBIENTE CONSTRUÍDO, 2., 2005, Maceió. Anais [...]. Porto Alegre: ANTAC, 2005, p. 250-259. 
CABÚS, R.; VÍTOR, P. TropLux 7: Guia do Usuário. Maceió: Instituto Lumeeiro, 2015.

CEI - COMMISSION INTERNATIONALE DE L'ECLAIRAGE. Guide to Recommended Practice of Daylight

Measurement. Technical Report. CIE 108. Vienna: Commission Internacionale de L'Eclairage, 1994.

CEI - COMMISSION INTERNATIONALE DE L'ECLAIRAGE. ISO 15469:2004(E)/CIE S 011/E:2003. Spatial distribution of daylight - CIE standard general sky. Vienna: Commission Internacionale de L'Eclairage, 2004.

CLIMATE.ONEBUILDING. 2018. Repository of free climate data for building performance simulation. South America-Region 3, BRA - Brazil. Disponível em: http://climate.onebuildin.org. Acesso em: 18 dez. 2018

DUFFIE, J. A.; BECKMAN, W. A. Solar Engineering of Thermal Processes. 1st edition; 4th edition. New York: John Wiley \& Sons, 2013.

FERREIRA, C. C.; SOUZA, R. V. G. de. Desenvolvimento de modelos matemáticos para a determinação da disponibilidade de luz natural no crepúsculo para a cidade de Belo Horizonte. Ambiente Construído, Porto Alegre, v. 13, n. 4, out./dez. 2013. DOI:http://dx.doi.org/10.1590/S1678-86212013000400004.

FERREIRA, F. F.; SOUZA, R. V. G. de. Determinação de céus típicos para minas gerais -metodologia de obtenção a partir de dados simplificados. In: ENCONTRO NACIONAL DE TECNOLOGIA NO AMBIENTE CONSTRUÍDO, 11., 2006, Florianópolis. Anais [...]. Porto Alegre: ANTAC, 2006, p. 364-371.

GOULART, S. V. G. Dados climáticos para avaliação de desempenho térmico de edificações em Florianópolis. 1993. 111 f. Dissertação (Mestrado em Engenharia Civil) - Universidade Federal de Santa Catarina, Florianópolis, 1993.

IBGE - INSTITUTO BRASILEIRO DE GEOGRAFIA E ESTATÍSTICA. Censo 2010, Resultados, Sinopse do censo demográfico 2010. População nos Censos Demográficos, segundo as Grandes Regiões e as Unidades da Federação 1872/2010. População em 2010, 2010. Disponível em:

http://www.cens02010.ibge.gov.br/sinopse/index.php?dados=4\&uf=00. Acesso em: 04 ago. 2017.

INMET - INSTITUTO NACIONAL DE METEOROLOGIA. Estações e dados. BPMED - Dados históricos. Banco de Dados Meteorológicos para Ensino e Pesquisa. Horas de insolação diária e mensal. 1997-2016a. Disponível em: http://www.inmet.gov.br/projetos/rede/pesquisa/inicio.php. Acesso em: 28 jun. a 3 jul. 2017.

INMET - INSTITUTO NACIONAL DE METEOROLOGIA. Banco de Dados Meteorológicos para Ensino e Pesquisa. Nebulosidade média (em décimos). 1997-2016b. Disponível em:

http://www.inmet.gov.br/projetos/rede/pesquisa/inicio.php. Acesso em: 28 jun. a 3 jul. 2017.

JULIAN, W. G. Daylighting standards, codes and policies. In: INTERNATIONAL DAYLIGHTING CONFERENCE, 1998, Ottawa. Proceedings [... ]. Ottawa: Ministry of Supply and Services Canada, 1998. p. 266-267.

KORACHAGAON, I.; BAPAT, V. N. General formula for the estimation of global solar radition on earth's surface around the globe. Renewable Energy, Great Britain, v. 41, p. 394-400, nov. 2011.

DOI:https://doi.org/10.1016/j.renene.2011.11.002

LABORATÓRIO DE EFICIÊNCIA ENERGÉTICA EM EDIFICAÇÕES (LabEEE). Arquivos climáticos em formato TRY, SWERA, CSV e BIN. [2005?]. Disponível em: http://www.labeee.ufsc.br/downloads/arquivos-climaticos/formato-tryswera-csv-bin. Acesso em: 05 ago. 2017.

LOU, S.; LI, D. H. W.; LAM, J. C. CIE Standard Sky classification by accessible climatic índices. Renewable Energy, Great Britain, v. 113, p. 347-356, jun. 2017. DOI: https://doi.org/10.1016/j.renene.2017.06.013

RANGARAJAN, S.; SWAMINATHAN, M. S.; MANI, A. Computation of solar radiation from observations of cloud cover. Solar Energy, Great Britain, v. 32, n. 4, p. 553-556, 1984. DOI: https://doi.org/10.1016/0038-092X(84)90270-6 
MICHEL, Mariana Vallory; LARANJA, Andréa Coelho.

Condições e tipos de céu para simulações de iluminação natural com céu estático

SOUZA, R. V. G. de; PEREIRA, F. O. R. Primeira estação de medição de iluminação natural em território brasileiro: análise dos dados dos dois primeiros anos de funcionamento. Ambiente Construído, Porto Alegre, v. 4, n. 3, p. 7994 , jul./set. 2004 .

SUPIT, I; VAN KAPPEL, R. R. A simple method to estimate global radiation. Solar Energy, Great Britain, v. 63, n. 3, p. 147-160, 1998. DOI: https://doi.org/10.1016/S0038-092X(98)00068-1

WU, W. et al. Spatial estimation of monthly mean daily sunshine hours and solar radiation across mainland China. Renewable Energy, Great Britain, v. 57, p. 546-553, mar. 2013. DOI: https://doi.org/10.1016/j.renene.2013.02.027

\section{${ }^{1}$ Mariana Vallory Michel}

Arquiteta e urbanista. MBA Gestão de Projetos em Engenharias e Arquitetura. Mestranda do Programa de PósGraduação em Arquitetura e Urbanismo na Universidade Federal do Espírito Santo. Endereço postal: Av. Fernando Ferrari, 514, Universidade Federal do Espírito Santo, Centro de Artes, Laboratório de Planejamento e Projetos, Vitória, ES, Brasil, 29075-910.

\section{${ }_{2}^{2}$ Andréa Coelho Laranja}

Arquiteta e urbanista. Doutora. Professora Adjunta da Universidade Federal do Espírito Santo no Curso de Arquitetura e Urbanismo. Endereço postal: Av. Fernando Ferrari, 514, Universidade Federal do Espírito Santo, Centro de Artes, Laboratório de Planejamento e Projetos, Vitória, ES, Brasil, 29075-910. 